\title{
Patterns and Influencing Factors of Medial Meniscus Tears in Varus Knee Osteoarthritis
}

\author{
Sung-Do Cho, MD, Yoon-Seok Youm, MD, Jong-Hyun Kim, MD, Hye-Yong Cho, MD, and Kwang-Ho Kim, MD
} Department of Orthopedic Surgery, Arthro Center, Ulsan University Hospital, University of Ulsan College of Medicine, Ulsan, Korea

\begin{abstract}
Purpose: To investigate the patterns of medial meniscus (MM) tears in patients with varus knee osteoarthritis who underwent total knee arthroplasty and analyze the factors that could affect MM tears.

Materials and Methods: The patients (365 knees, 268 patients) were classified into three groups; group I with MM posterior horn (PH) tear only; group II with MM root tear only; and group III with MMPH plus root tear. The following factors were evaluated: age, gender, body mass index, varus deviation of the mechanical axis, medial proximal tibial angle, posterior tibial slope (PTS), and anterior cruciate ligament (ACL) integrity (normal, degeneration, and tear or absence).

Results: MM tears were identified in all knees. The patterns of the combined MMPH tears in group III were less complex than those in group I. Varus deviation and PTS were significantly greater in group III than groups I and II. In group III, there were significantly more cases of ACL tear or absence than groups I and II. The others showed no differences among three groups.

Conclusions: Severe varus knee osteoarthritis was always accompanied by MM tears. Risk factors for MMPH plus root tears were severe varus deformity, great PTS, and ACL tear or absence.
\end{abstract}

Keywords: Knee, Osteoarthritis, Varus, Medial meniscus, Tear

\section{Introduction}

The weight distribution function of the meniscus is maintained primarily by circumferential hoop tension, the loss of which has been extensively implicated in the development of osteoarthritis $^{1-3)}$. Several studies have demonstrated that the loss of hoop tension in knees with root tears of the medial meniscus (MM) would cause uneven weight distribution across the knee, eventually resulting in progression of osteoarthritis ${ }^{4-7)}$.

On the other hand, it has been suggested that it is the progres-

Received July 19, 2015; Revised October 27, 2015;

Accepted November 25, 2015

Correspondence to: Yoon-Seok Youm, MD

Department of Orthopedic Surgery, Ulsan University Hospital, 877

Bangeojinsunhwan-doro, Dong-gu, Ulsan 44033, Korea

Tel: +82-52-250-7129, Fax: +82-52-235-2823

E-mail: tkra@naver.com

This is an Open Access article distributed under the terms of the Creative Commons Attribution Non-Commercial License (http://creativecommons.org/licenses/by-nc/4.0/) which permits unrestricted non-commercial use, distribution, and reproduction in any medium, provided the original work is properly cited. sion of osteoarthritis that affects the integrity of the meniscus and adjacent tissues resulting in degenerative tears of the meniscus and cruciate ligaments ${ }^{8)}$. In other words, meniscus tears are considered both a cause and a consequence of osteoarthritis, and the etiology and pathogenesis have not been clearly established. In addition, tear patterns and risk factors for meniscus tears in severe osteoarthritis have rarely been documented.

In this study, we investigated the presence and patterns of MM tears in patients with severe varus osteoarthritis during total knee arthroplasty (TKA) and explored the factors that could affect the patterns of MM tears.

\section{Materials and Methods}

We reviewed 268 patients (365 knees; 33 males and 235 females) who underwent TKA under the diagnosis of KellgrenLawrence grade IV varus knee osteoarthritis between July 2012 and May 2014 at our institution. The exclusion criteria included Kellgren-Lawrence grade III or IV osteoarthritis in the lateral compartment of the knee, a history of previous ipsilateral knee 
surgery, and traumatic arthritis of the knee.

The MM tear patterns were assessed intraoperatively by one surgeon (SDC). According to the tear pattern, patients were classified into three groups; group I with a posterior horn tear only (Fig. 1); group II with a root tear only (Fig. 2); and group III with a posterior horn tear and a root tear (Fig. 3).

Patients' age, gender, and body mass index (BMI) were compared. Using the picture archiving and communications system (PiView STAR software, Infinitt, Seoul, Korea), the medial proximal tibial angle (MPTA) and posterior tibial slope were assessed on the anteroposterior and lateral radiographs of the knee. The

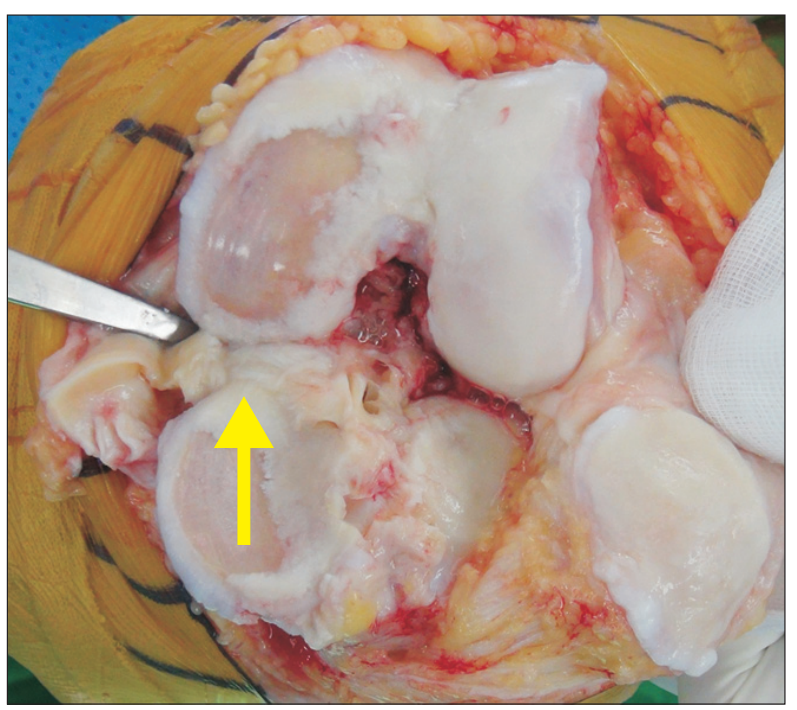

Fig. 1. Complex tear of the medial meniscus posterior horn (arrow).

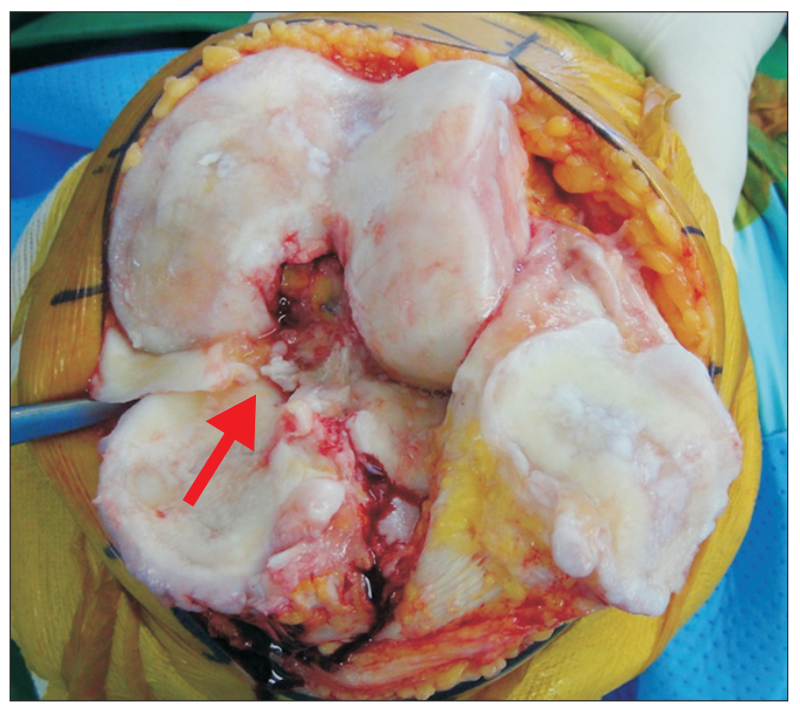

Fig. 2. Root tear (radial tear near the posterior tibial origin site) of the medial meniscus (arrow). extent of varus deviation of the mechanical axis was evaluated on the anteroposterior weight-bearing full-length radiographs. The MPTA was measured as the angle between the anatomical axis of the tibia and the articular surface. The posterior tibial slope was assessed by measuring the angle between the anatomical axis of the tibia and the medial tibial plateau. The extent of varus deviation was evaluated by measuring the angle formed by a line from the center of the femoral head to the center of the knee and a line from the center of the knee to the center of the ankle.

The integrity of the anterior cruciate ligament (ACL) was assessed intraoperatively and categorized into normal, degenerative, and torn/absent. The ACL integrity was compared among the three groups to determine its relationship with the tear pattern.

All statistical analyses were performed using IBM SPSS ver. 21.0 (IBM Co., Armonk, NY, USA). Chi-square and analysis of variance tests were used to determine statistical significance. A pvalue $<0.05$ was considered statistically significant.

\section{Results}

MM tears were identified in all patients included in the study. In group I with MM posterior horn tears only (191 knees, 52.3\%), most of the tears were complex (182 knees, 95.3\%) (Table 1) and extended to the periphery (159 knees, $83.2 \%$ ). Group II with root tears only consisted of 87 knees (23.8\%). Group III with posterior horn tears and root tears was composed of 87 knees $(23.8 \%)$; the combined posterior horn tears were complex in 38 knees (43.7\%), horizontal in 40 knees (46.0\%), and radial in 9 knees (10.3\%)

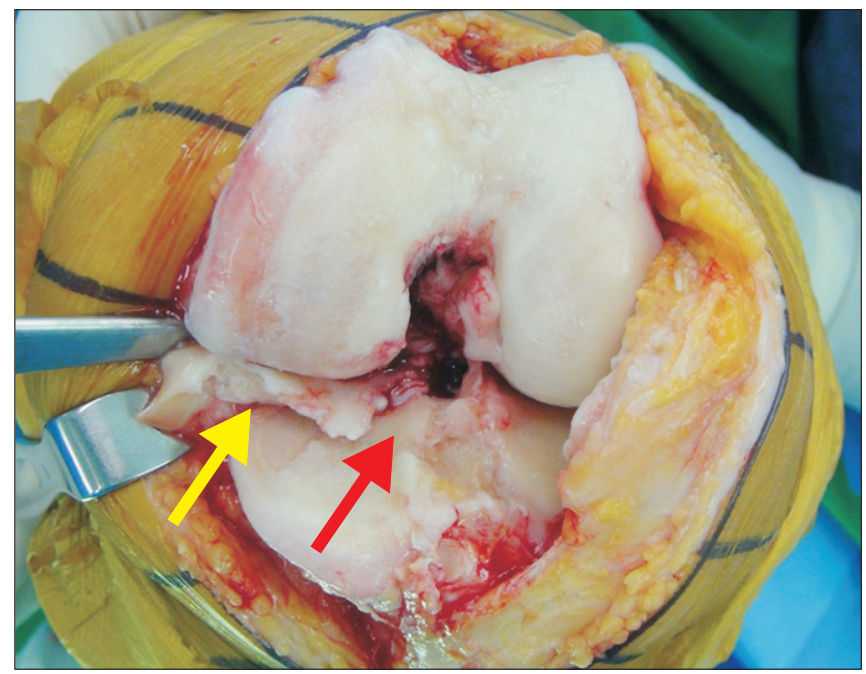

Fig. 3. Medial meniscus posterior horn tear (yellow arrow) plus root tear (red arrow). 
(Table 1). Compared to group I, posterior horn tears in group III were relatively simple and extension to the periphery was less frequent (42 knees, 48.3\%).

With regard to age, gender, and BMI, there was no statistically significant difference among the groups ( $>>0.05$ ) (Table 2$)$. The mean MPTA was not significantly different among three groups (Table 2). The mean varus deviation of the mechanical axis of the lower extremity was $17^{\circ}$ (range, $0^{\circ}$ to $27^{\circ}$ ) in group I, $13.5^{\circ}$ (range, $1^{\circ}$ to $22^{\circ}$ ) in group II, and $28.7^{\circ}$ (range, $0^{\circ}$ to $29^{\circ}$ ) in group III, indicating more varus malalignment of group III compared to groups I and II $(\mathrm{p}<0.05)$ (Table 2$)$. The mean posterior tibial slope was significantly greater in group III $\left(13.5^{\circ}\right.$ [range, $1^{\circ}$ to $\left.\left.24^{\circ}\right]\right)$ than in group I $\left(11.0^{\circ}\right.$ [range, $0^{\circ}$ to $\left.\left.22^{\circ}\right]\right)$ and group II $\left(11.2^{\circ}\right.$ [range, $1^{\circ}$ to $20^{\circ}$ ]) $(\mathrm{p}<0.05)$ (Table 2$)$. The prevalence of intact ACL during operation was significantly high in group I compared to groups II and III; the incidence of ACL tear or absence was remarkably high in group III compared to groups I and II $(\mathrm{p}<0.05)$ (Table 3).

\section{Discussion}

The results of the current study have shown that MM tears are always present in severe varus knee osteoarthritis and MM root tears are frequently accompanied by posterior horn tears in knees with severe varus malalignment, great posterior tibial slope, and ACL tears.

The major functions of the meniscus include weight distribution, shock absorption, load transmission, and joint lubrication.

Table 1. Tear Patterns of the Medial Meniscus

\begin{tabular}{|c|c|c|c|c|c|}
\hline \multirow{2}{*}{ Variable } & \multicolumn{3}{|c|}{ Posterior horn tear (\%) } & \multirow{2}{*}{$\begin{array}{l}\text { Root } \\
\text { tear }\end{array}$} & \multirow{2}{*}{$\begin{array}{c}\text { Extension to } \\
\text { periphery (\%) }\end{array}$} \\
\hline & Complex & Horizontal & Radial & & \\
\hline Group I & $182(95.3)$ & $7(3.7)$ & $2(1.0)$ & 0 & $159(83.2)$ \\
\hline Group II & 0 & 0 & 0 & 87 & 0 \\
\hline Group III & $38(43.7)$ & $40(46.0)$ & $9(10.3)$ & 87 & $42(48.3)$ \\
\hline
\end{tabular}

In addition, this wedge-shaped structure improves congruity between the femur and the tibia, protects adjacent articular cartilage, and contributes to the stability of the knee joint ${ }^{9,10)}$. In knees with advanced osteoarthritis, the meniscus serves the protective function even in degenerative condition by maintaining consistent association between the remnants of the meniscus and the well-preserved or the large amount of remaining articular cartilage ${ }^{11)}$. Noble and Hamblen ${ }^{12)}$ reported that the protective function was maintained even in knees with degenerative meniscus lesions.

Several recent studies have described the loss of hoop tension in knees with MM root tears as the cause of degenerative osteoarthritis $^{4-7)}$. Bin et al. ${ }^{5)}$ reported that $27.8 \%$ of the MM tears were radial tears of the MM posterior horn. Nha et al. ${ }^{13)}$ identified MM root tears in $32.5 \%$ of their patients and the prevalence was higher in the MM than in the lateral meniscus, which they attributed to the lesser mobility of the tibial attachment of the posterior horn of the MM than that of the lateral meniscus. On the other hand, Arno et al. ${ }^{14)}$ suggested that changes in the tibiofemoral contact mechanics could result in articular cartilage degeneration in knees with horizontal cleavage lesions unaccompanied by loss of hoop tension.

In our study, MM root tears were identified in 174 (47.7\%) of the 365 knees. Of these, the lesions were not combined with other tears in 87 knees (50\%), whereas MM posterior horn tears were also present in the remaining 87 knees (50\%). In varus knee osteoarthritis without root tears, complex tears of the MM poste-

Table 2. Statistically Nonsignificant Variables of Each Group

\begin{tabular}{|c|c|c|c|c|c|}
\hline \multirow{2}{*}{ Variable } & \multirow{2}{*}{ Age (yr) } & \multicolumn{2}{|c|}{ Gender } & \multirow{2}{*}{ BMI $\left(\mathrm{kg} / \mathrm{m}^{2}\right)$} & \multirow{2}{*}{$\operatorname{MTPA}\left({ }^{\circ}\right)$} \\
\hline & & $\mathrm{M}$ & $\mathrm{F}$ & & \\
\hline Group I & $64.0(49-87)$ & 29 & 162 & $29.6(18.3-37.5)$ & $81.1(72.5-94.0)$ \\
\hline Group II & $67.5(52-81)$ & 7 & 80 & $30.3(18.0-36.9)$ & $85.7(68.1-91.0)$ \\
\hline Group III & $73.5(48-80)$ & 6 & 81 & $28.7(17.7-33.2)$ & $87.7(70.0-93.0)$ \\
\hline
\end{tabular}

Table 3. Factors That Affect the Medial Meniscus Tear

\begin{tabular}{lccccc}
\hline Variable & MA $\left({ }^{\circ}\right)^{\mathrm{a})}$, mean $($ range $)$ & PTS $\left({ }^{\circ}\right)^{\mathrm{b})}$, mean $($ range $)$ & \multicolumn{2}{c}{ ACL $(\%)^{\mathrm{c})}$} \\
\cline { 4 - 6 } & $17.0(0-27)$ & $11.0(0-22)$ & $107(56.0)$ & Degeneration & Tear or absence \\
\hline Group I & $13.5(1-22)$ & $11.2(1-22)$ & $36.1)$ & $15(7.9)$ \\
Group II & $28.7(0-29)$ & $13.5(1-24)$ & $30(34.5)$ & $34(44.8)$ & $12(13.8)$ \\
Group III & & & $39.1)$ & $23(26.4)$ \\
\hline
\end{tabular}

MA: mechanical axis, PTS: posterior tibial slope, ACL: anterior cruciate ligament.

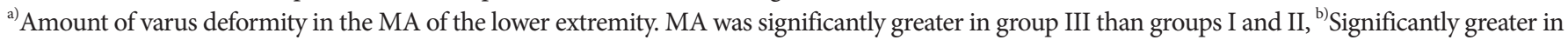
group III than groups I and II, ${ }^{c}$ There were significantly more cases of ACL tear or absence in group III than groups I and II. 
rior horn (95.3\%) were prevalent and extension to the periphery $(83.2 \%)$ was frequently noted. In contrast, posterior horn tears accompanying posterior root tears were relatively simple in pattern $(56.3 \%)$ and did not extend to the periphery in many cases (48.3\%). In knees with an MM posterior root tear, subluxation of the MM during weight-bearing causes loss of weight distribution function of the meniscus and increased pressure on the contact surface. It is our understanding that while this could accelerate degeneration of the articular cartilage, due to the reduced load on the MM, the tear pattern becomes simple and does not extend to the periphery.

Hwang et al. ${ }^{15)}$ described female sex, high BMI, and great varus alignment as the risk factors for MM posterior root tears. Choi and Park ${ }^{16)}$ reported MM posterior root tears were associated with varus deformity, mechanical axis deviation, and BMI. In our study, we could not identify any relationship of MM posterior root tears with gender and BMI, but varus deviation was correlated with the incidence of MM posterior horn tears accompanied by radial tears of the MM posterior root. With regard to the MPTA, there was no significant difference among three groups, whereas group III exhibited notably greater varus deviation of the mechanical axis. This indicates that varus alignment of the lower extremity than varus deformity of the proximal tibia has greater influence on the MM tear pattern. The posterior tibial slope was significantly greater in group III with an MM posterior horn tear plus a root tear than groups I and II. The incidence of ACL tear or absence was higher in group III than in groups I and II. Therefore, it seems reasonable to expect a correlation of the extent of MM tears with posterior tibial slope and presence of ACL injuries. Although the mechanism of injury has not been definitely determined, our findings suggest that the increased shear force on the MM could be responsible for MM tears, which should be verified in further research.

The strength of this study is the prospective design. On the other hand, a limitation of this study is that the tear patterns were determined solely by one investigator, and thus there was no adequate inter-rater reliability test performed. The direction of the causal relationship between the occurrence/progression of varus knee osteoarthritis and MM tears has not been elucidated in this study; however, one of the major findings was that MM tears were present in all knees with severe varus knee osteoarthritis, which warrants further research on the relationship between osteoarthritis and MM tears.

\section{Conclusions}

Severe varus knee osteoarthritis was always accompanied by MM tears. Risk factors for MM root tears combined with posterior horn tears were severe varus deformity of the lower extremity, great posterior tibial slope, and ACL tear or absence.

\section{Conflict of Interest}

No potential conflict of interest relevant to this article was reported.

\section{References}

1. Bessette GC. The meniscus. Orthopedics. 1992;15:35-42.

2. Fukuda Y, Takai S, Yoshino N, Murase K, Tsutsumi S, Ikeuchi K, Hirasawa Y. Impact load transmission of the knee joint-influence of leg alignment and the role of meniscus and articular cartilage. Clin Biomech (Bristol, Avon). 2000;15: 516-21.

3. Walker PS, Erkman MJ. The role of the menisci in force transmission across the knee. Clin Orthop Relat Res. 1975; (109):184-92.

4. Allaire R, Muriuki M, Gilbertson L, Harner CD. Biomechanical consequences of a tear of the posterior root of the medial meniscus. Similar to total meniscectomy. J Bone Joint Surg Am. 2008;90:1922-31.

5. Bin SI, Kim JM, Shin SJ. Radial tears of the posterior horn of the medial meniscus. Arthroscopy. 2004;20:373-8.

6. Ozkoc G, Circi E, Gonc U, Irgit K, Pourbagher A, Tandogan $\mathrm{RN}$. Radial tears in the root of the posterior horn of the medial meniscus. Knee Surg Sports Traumatol Arthrosc. 2008; 16:849-54.

7. Guermazi A, Hayashi D, Jarraya M, Roemer FW, Zhang Y, Niu J, Crema MD, Englund M, Lynch JA, Nevitt MC, Torner JC, Lewis CE, Felson DT. Medial posterior meniscal root tears are associated with development or worsening of medial tibiofemoral cartilage damage: the multicenter osteoarthritis study. Radiology. 2013;268:814-21.

8. Englund M, Guermazi A, Lohmander SL. The role of the meniscus in knee osteoarthritis: a cause or consequence? Radiol Clin North Am. 2009;47:703-12.

9. Hsieh HH, Walker PS. Stabilizing mechanisms of the loaded and unloaded knee joint. J Bone Joint Surg Am. 1976;58:8793.

10. Levy IM, Torzilli PA, Warren RF. The effect of medial men- 
iscectomy on anterior-posterior motion of the knee. J Bone Joint Surg Am. 1982;64:883-8.

11. Fahmy NR, Williams EA, Noble J. Meniscal pathology and osteoarthritis of the knee. J Bone Joint Surg Br. 1983;65:24-8.

12. Noble J, Hamblen DL. The pathology of the degenerate meniscus lesion. J Bone Joint Surg Br. 1975;57:180-6.

13. Nha KW, Jo JH, Lee DB. Clinical results of the radial tear of posterior root of medial meniscus. J Korean Arthrosc Soc. 2007;11:128-33.

14. Arno S, Bell CP, Uquillas C, Borukhov I, Walker PS. Tibio- femoral contact mechanics following a horizontal cleavage lesion in the posterior horn of the medial meniscus. J Orthop Res. 2015;33:584-90.

15. Hwang BY, Kim SJ, Lee SW, Lee HE, Lee CK, Hunter DJ, Jung KA. Risk factors for medial meniscus posterior root tear. Am J Sports Med. 2012;40:1606-10.

16. Choi ES, Park SJ. Clinical evaluation of the root tear of the posterior horn of the medial meniscus in total knee arthroplasty for osteoarthritis. Knee Surg Relat Res. 2015;27:90-4. 